\title{
ENERGY CONSUMPTION OF DEFROSTING PROCESS IN NO-FROST REFRIGERATORS
}

\author{
D. B. Özkan ${ }^{1}$, F. Ünal ${ }^{2, *}$
}

\begin{abstract}
Refrigerators have high energy consumption because they consume energy throughout the day, and they are used in all residences and in most offices. Designing more efficient models and, thus, decreasing the energy consumption of refrigerators have become necessary, owing to the global energy scarcity. The purpose of this study was to decrease energy consumption and increase the efficiency of the defrosting process in no-frost refrigerators. The defrosting process plays an important role in the energy consumption of no-frost refrigerators. The amount of energy needed for defrosting and the time it takes are important factors for manufacturers in terms of energy performance. Recently, a theoretical correlation was developed as a function of the frost thickness, heat flux, and frost density for estimating the defrosting time of an evaporator fin surface. The melting time of the frost on the fin was calculated by a mathematical model and compared to results that were obtained experimentally. The results were differed from the actual melting time as $4.7 \%$.
\end{abstract}

\section{Keywords: Energy Consumption of Refrigerator, Defrosting Process, Energy Saving in Refrigerator}

\section{INTRODUCTION}

Recently, the production of energy-efficient products in the white goods sector has been studied. Because there are refrigerators in all homes and most commercial buildings, they consume much energy. A refrigerator consumes, on average, $1.07 \mathrm{kWh}$ every $24 \mathrm{~h}$ in a $32^{\circ} \mathrm{C}$ environment (A+ product). When the energy consumption of a refrigerator is compared with the electric consumption values for 2015 provided by the Turkish Government Statistics Institute (DIE), the values are $22 \%$ of the entire residential electric consumption [1]. Therefore, energy consumption by refrigerators has recently attracted considerable attention for technological change worldwide. The factors responsible for this change include the establishment of minimum energy performance standards and various utility objectives to encourage consumers to use energy-efficient units. The impact of standards would be eventually to eliminate the least-efficient products on the market. Recently, refrigerator manufacturers have attempted to reduce the energy consumption of refrigerators and to design moreefficient models, so it is important to forecast and understand the energy consumption behaviour of these devices. The defrosting process is an important process that consumes energy in no-frost refrigerators [2]. In this context, when the studies in the literature are examined, Patil et al. [3] have reviewed heat transfer characteristics of the heat exchangers for refrigeration, air conditioning, and heat pump systems under frosting, defrosting, and dry/wet conditions. This contributes to research on snow defrosting. Saidur et al. [4] studied the effects of room temperature, door opening, and thermostat installation position on the energy consumption of refrigerators. Mader and Thybo [5] studied evaporator coils for air heat pumps. Results showed that the below-standard frost state of the evaporator can eliminate frost, and also other states were more efficient. Finally, the efficiency of the system increased significantly. Ge et. al. [6] examined a system with a desiccant-coated heat exchanger for handling the latent and sensible load for the excess released adsorption heat in the dehumidification process with a dynamic one-dimensional mathematical model. The results demonstrated that the operation time in the dehumidification process is a crucial factor for the cooling capacity of the system. Finally, a model was used for analysing structural parameters. Lawrence and Evans [7] examined the results of testing an algorithm that detects the need for a defrost of the refrigerant pattern (or evaporator exit superheat). The algorithm enables the number of defrosts to be reduced without excessively raising the temperature of food stored in the cabinet. In this context, the reductions in energy and carbon dioxide were examined and were shown to be substantial. Li et al.[8] examined based on the idea of making the frost absorb most of the heat generated by electric heater, a new 
method of defrosting is proposed, and its principle is to make the defrosting process at different locations complete simultaneously by optimizing the frost mass distribution on the evaporator. In this method, the defrosting heat distribution on evaporator surface, the required frost mass distribution, the required air flow distribution and the structure of return air duct are determined, respectively. Application of this method in an actual household refrigerator shows that the defrosting efficiency is improved by $29.8 \%$. Yoon et al.[9] examined three adaptive defrosting methods to control the heater by using the information of the temperature sensor, during the defrosting process of the household refrigerator. In their study the effects of the conduction heater, and radiation heater, on the increase in freezer temperature, were investigated. The optimized defrosting method diminished the increase in the freezer temperature and confirmed the energy saving effect by improving the defrosting efficiency. A range of papers have investigated the defrosting process in great detail to ascertain the overall defrosting efficiency and to research ways to reduce the associated energy consumption. Several authors noted that the overall efficiency of the frosting process is low at around $20-30 \%$, based on laboratory experiments [10-14]. In this study, unlike other studies, a formulation was developed to calculate the duration of the frost melting on the evaporator side for defrosting, which is one of the factors affecting the energy consumption of refrigerators. Theoretical and experimental results are compared according to the determined mathematical model. According to the results, recommendations for energy savings during defrosting are given.

\section{DEFROSTING PROCESS}

Frost forms on evaporator coils from water vapour in the air condensing and freezing when the surface temperature of the coil falls below $0^{\circ} \mathrm{C}$. Frost accumulated on the evaporator surface acts as a thermal insulator and prevents the flow of heat. Therefore, frost has an important effect on evaporator performance. At the same time, the refrigerator works "harder" as the compressor uses more electrical power to maintain the cold space at the prescribed temperature level. Therefore, the frost on the evaporator surface must be melted at predetermined intervals. This melting process is called defrosting. The evaporator needs to be defrosted periodically to maintain system performance and temperature control. The most commonly used defrost method is refrigerated electric defrost. In electric defrost, the thermal energy to melt the ice is provided by an electric strip heater that is situated across the face of the coil. The amount of energy needed for defrosting and the time it takes are important factors for manufacturers because of energy consumption. The defrosting time in refrigerators should not exceed a certain period. This is because the cooling of the refrigerator stops during defrosting and also the additional heat from the defrosting heater enters the cabin. Defrosting time changes depending on the amount of frost on the evaporator, frost density, and heat flux.

\section{MELTING TIME OF FROST ON FIN}

Figure 1 shows the melting process of frost on the fin. The model in this study consists of two parts. In the first part, the time when the fin reaches the temperature to melt the frost is calculated. In the second part, the melting time of the frost on the fin is calculated by a mathematical model.

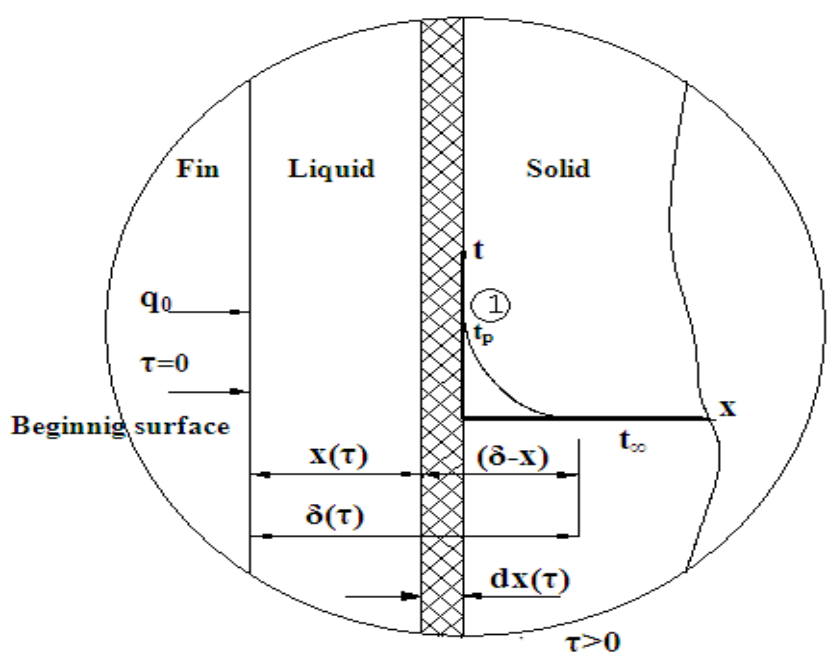

Figure 1. Melting process of frost on fin 
The defrosting time of the evaporator fin surface was calculated in two steps. The first step was the calculated time of fin surface temperature up to $0^{\circ} \mathrm{C}$ with constant heat flux.

$$
q_{0} \tau_{1}=\rho c_{p} l \Delta T
$$

In this equation, $\rho_{\mathrm{Al}}$ is the $\mathrm{Al}$ density $\left(\mathrm{kg} / \mathrm{m}^{3}\right), \mathrm{cp}_{\mathrm{Al}}$ is the $\mathrm{Al}$ specific heat at constant pressure $(\mathrm{J} / \mathrm{kg} \mathrm{K}), \tau_{1}$ is the time of fin surface temperature up to $0^{\circ} \mathrm{C}$ constant heat at flux (min), $\mathrm{q}_{\mathrm{o}}$ is heat flux (W/ $\mathrm{m}^{2}$ ), 1 is the fin thickness $(\mathrm{m})$, and $\Delta \mathrm{T}$ can be written as below:

$$
\Delta T=T 1-T 2
$$

In Equation 2, $\mathrm{T}_{1}$ is the frost melting temperature $(273 \mathrm{~K})$ and $\mathrm{T}_{2}$ is the fin temperature before the beginning of defrosts $(\mathrm{K})$.

The second step is the calculated time for melting the frost. Process period $\frac{d x}{d \tau} \rightarrow$ constant and $(\delta-x) \rightarrow$ constant have a steady-state solution. Therefore, from

$$
\frac{d x}{d \tau}=A=\frac{q_{0} / 2}{\rho_{f}\left(Q_{L}+c_{f} \cdot v_{p}\right)}
$$

the equation can be calculated. $\mathrm{V}_{\mathrm{p}}$ can be written as:

$$
v_{p}=T_{1}-T_{\infty}
$$

In the equations above, $\mathrm{c}_{\mathrm{f}}$ is the specific heat of frost $(\mathrm{J} / \mathrm{kg} \mathrm{K}), \mathrm{T}_{1}$ is the melting temperature of frost $(\mathrm{K})$, $\mathrm{T}_{\infty}$ is the frost temperature $(\mathrm{K}), \mathrm{dx}$ is the frost thickness on the fin $(\mathrm{m})$, and $\tau$ can be written as below.

$$
\tau=\tau_{1}-\tau_{2}
$$

In this equation, $\tau$ is the defrosting time ( $\min )$ and $\tau_{2}$ is the melting time $(\mathrm{min})$.

\section{RESULTS AND DISCUSSION}

The results obtained from the mathematical model and experiments were compared. The defrosting time related to heat flux for a $152-\mathrm{kg} / \mathrm{m}^{3}$ frost density is given in Figure 2.

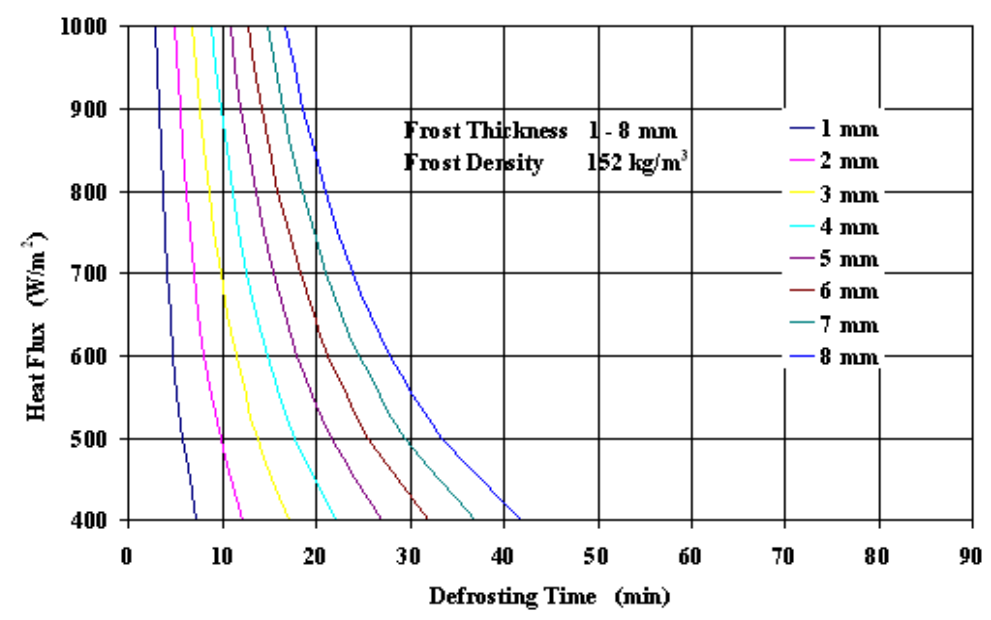

Figure 2. Defrosting time related to heat flux (frost density $152 \mathrm{~kg} / \mathrm{m}^{3}$ ) 
In Figure 2, it is seen that heat flux at higher values affects the melting time insignificantly. This situation is more often seen, because the thickness of frost is especially low. It is seen that the given heat flow affects the melting time of frost more when the thickness of the frost increases. When the thickness is low giving increased heat flow, the melting time is affected less. For example, setting the heat flow for frost of 3-mm thickness as $1000 \mathrm{~W} / \mathrm{m} 2$ instead of $700 \mathrm{~W} / \mathrm{m} 2$ decreases the melting time by $2 \mathrm{~min}$. Therefore, when designing the heat flux of the defrosting heater, these optimisations should be considered. The relationship of the defrosting time to the frost thickness and heat flux for a $152 \mathrm{~kg} / \mathrm{m} 3$ frost density is given in Figure 3 .

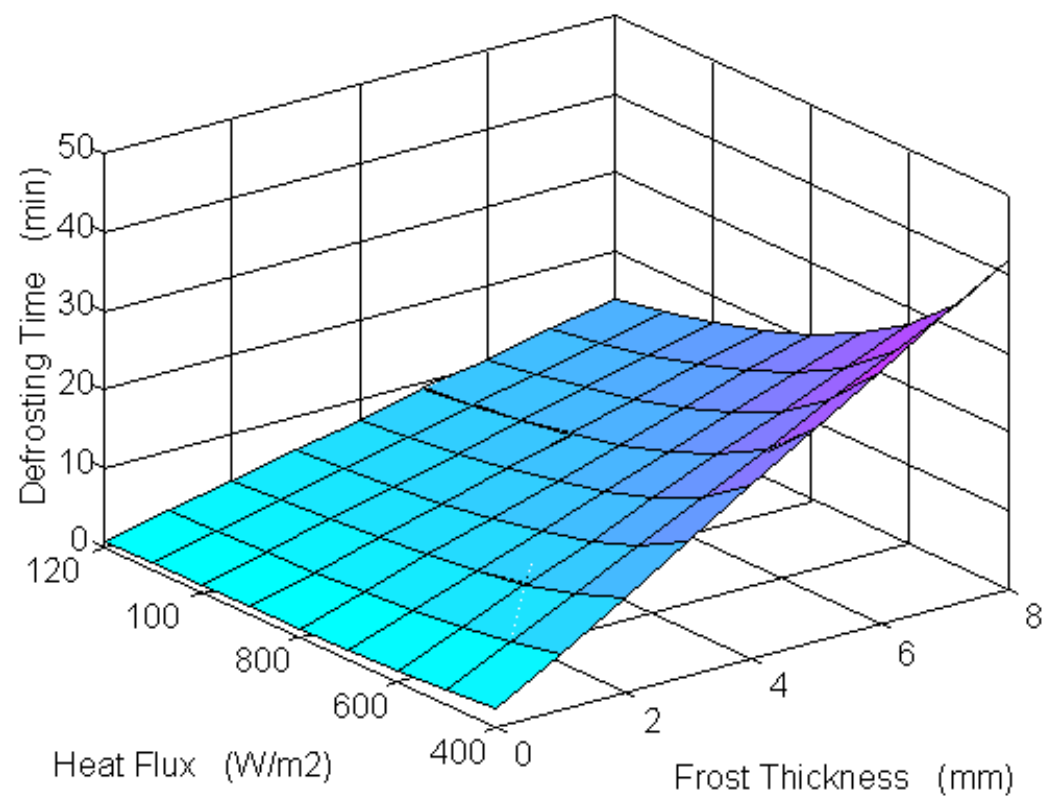

Figure 3. Relationship of defrosting time to frost thickness and heat flux (frost density $152 \mathrm{~kg} / \mathrm{m}^{3}$ )

Figure 3 shows the relationship among heat flux, frost thickness, and melting time at 2 min. According to this, as the thickness of the frost increases, the defrosting time increases too, and, as heat flux increases, the melting time increases. We can use these criteria while designing a defrosting heater for a refrigerator.

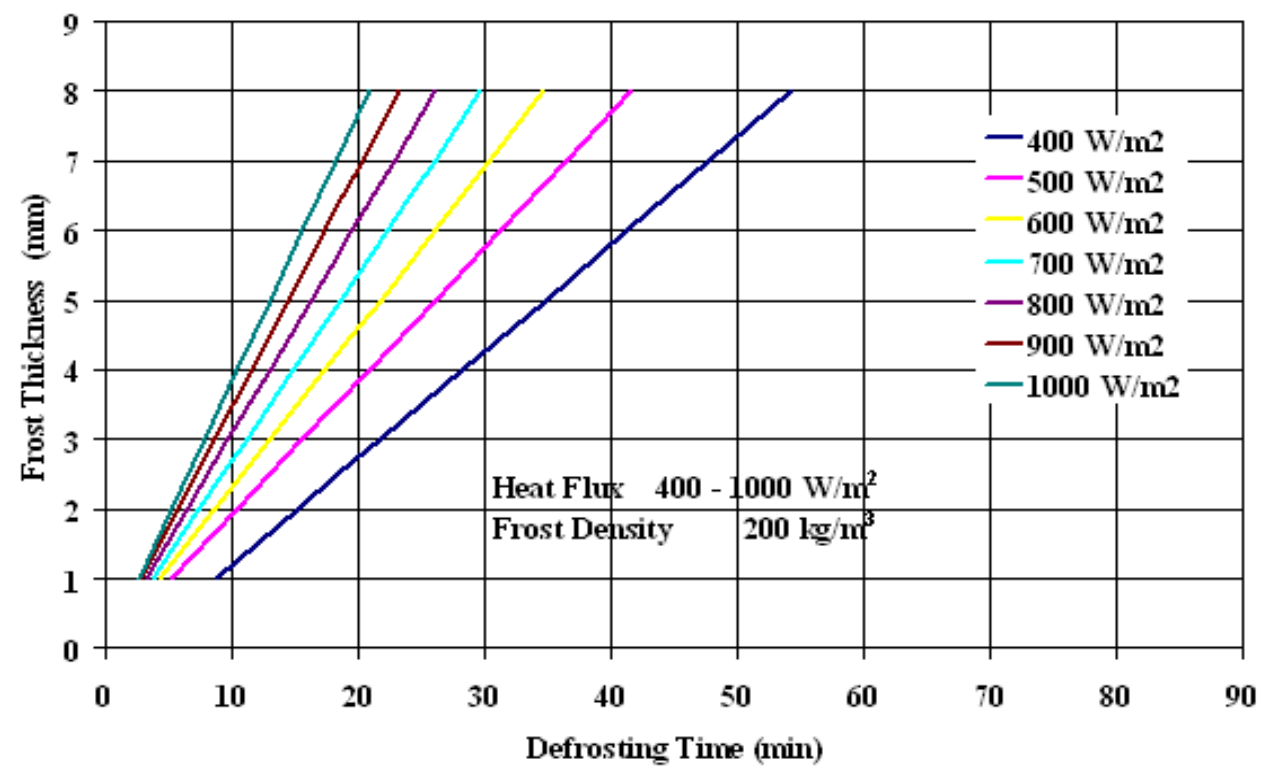

Figure 4. Defrosting time related to frost thickness (frost density of $200 \mathrm{~kg} / \mathrm{m}^{3}$ ) 
When a no-frost refrigerator is operated in the designed environmental conditions and the evaporation temperature is $-25^{\circ} \mathrm{C}$, the density of the frost on the evaporator was found to be $152 \mathrm{~kg} / \mathrm{m}^{3}\left(\mathrm{t}_{\text {ort. }}=22^{\circ} \mathrm{C}, \varphi=\right.$ $65 \%$ ). From the experiments, it was observed that, as the evaporation temperature decreased, the frost that forms on the evaporator shifted from a needle-like state to a denser state. In Figure 4, optimization for a frost density of $200 \mathrm{~kg} / \mathrm{m}^{3}$ is shown. The density increases as the melting time of the frost increases. The time-specific humidity change of the air within the refrigerator is given in Figure 5.

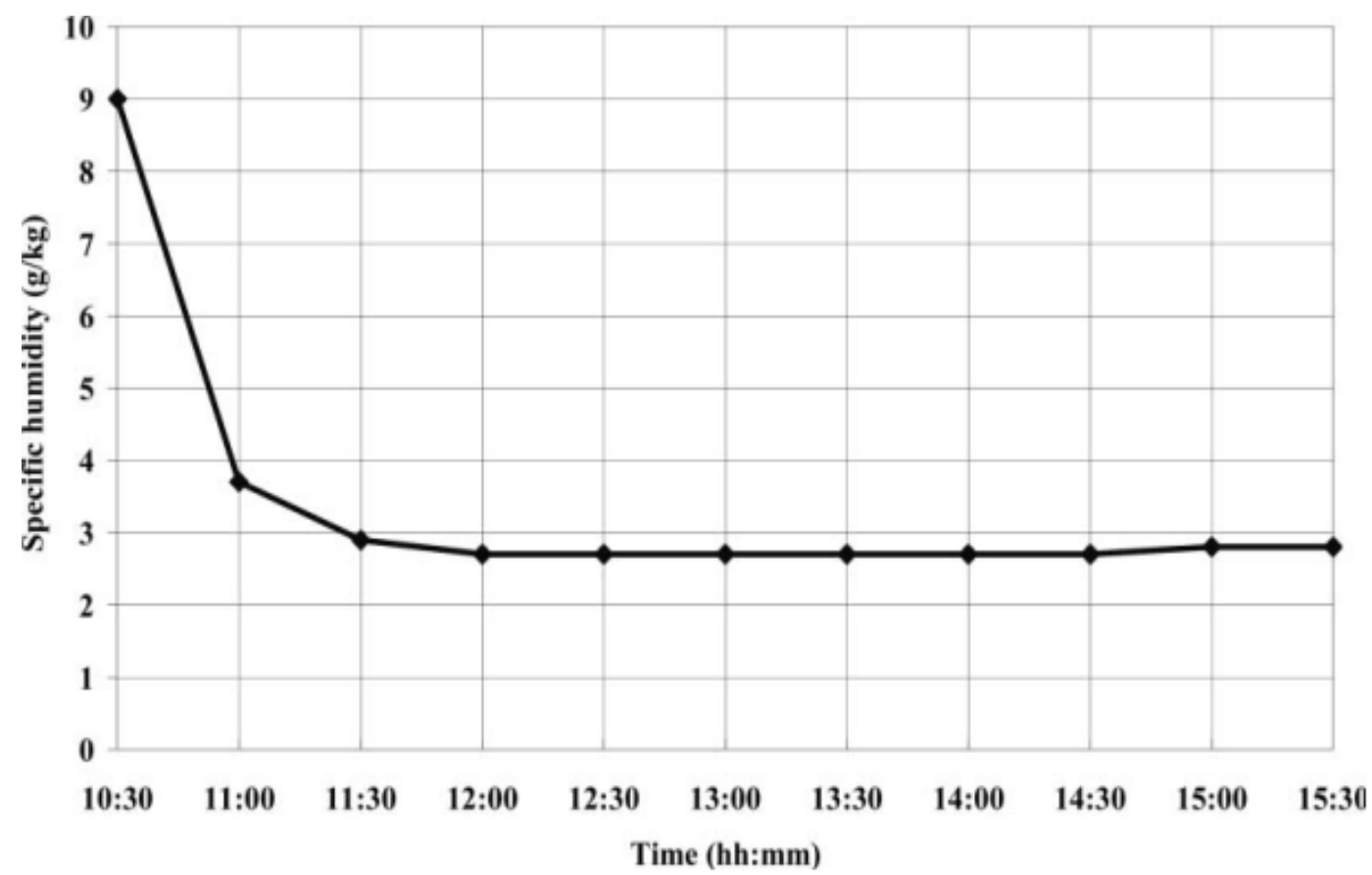

Figure 5. The change of specific humidity of the cabin with respect to time

In Figure 5, it can be observed that there was a rapid reduction in the specific humidity value during the first $30 \mathrm{~min}$ of cooling. The specific humidity value remained the same for a period beginning $1.5 \mathrm{~h}$ after the start of cooling until the end of experiment.

\section{CONCLUSIONS}

A theoretical formulation for calculating the melting time of frost on the fin of the evaporator of a nofrost refrigerator was developed. The model consists of two parts. In the first part, the time for the fin to reach the temperature to melt the frost is calculated. In the second part, the melting time of the frost on the fin is calculated using the mathematical model, and the results are obtained from the experiment and compared. The results differ \% 4.7 from the actual melting time. From the results obtained using the mathematical model, it can be seen that for the defrosting time of two frost layers of the same thickness, the layer that is denser has a longer defrosting time. The defrosting time in refrigerators should not exceed a certain period. This is because the cooling of the refrigerator stops during defrosting, and also the additional heat from the defrosting heater enters the cabin. This causes the temperature inside the cabin to exceed a certain value, and stored food will begin to decompose. To decrease the melting time, it is necessary to increase the heat flow to a reasonable amount.

According to these results, to save energy during the defrosting process, the following precautions should be considered.

- The evaporator should be divided into sections, and defrosting should be done separately by using different heaters.

- The frost in certain areas of the evaporator should be melted by rearranging the dimensions of the pipe through which the cooling fluid flows, directing the air that comes from the fresh food area and causes a high level of frosting by using a lapel, or by using a valve for the cooling fluid and therefore defrosting only a certain area. 


\section{NOMENCLATURE}

A Surface area $\left[\mathrm{m}^{2}\right]$

c Specific heat $[\mathrm{J} / \mathrm{kg} \mathrm{K}]$

$m \quad$ Mass flow $[\mathrm{kg} / \mathrm{s}]$

$Q, \mathrm{q} \quad$ Heat flux $\left[\mathrm{W} / \mathrm{m}^{2}\right]$

$T$ Temperature $\left[{ }^{\circ} \mathrm{C}, \mathrm{K}\right]$

$T_{\infty} \quad$ Frost temperature $\left[{ }^{\circ} \mathrm{C}, \mathrm{K}\right]$

$\Delta T \quad$ Temperature difference $\left[{ }^{\circ} \mathrm{C}, \mathrm{K}\right]$

$\tau \quad$ Time $[\mathrm{min}]$

$\rho \quad$ Density $\left[\mathrm{kg} / \mathrm{m}^{3}\right]$

$\varphi \quad$ Humidity

$\tau_{1} \quad$ Defrosting time [min]

$\tau_{2} \quad$ Melting time [min]

$l \quad$ Thickness $[\mathrm{m}]$

$c_{f} \quad$ Specific heat of defrost $[\mathrm{J} / \mathrm{kgK}]$

$f \quad$ Frost

\section{REFERENCES}

[1] 1. DIE, (2015). Elektrik Enerjisi Tüketiminin Sektörel Dağı̆lımı, Devlet İstatistik Enstitüsü, Ankara.

[2] Eckert, E., Drake, R., (1987). Analysis of Heat and Mass Transfer, McGraw-Hill Book Company, USA.

[3] Patil, M., S., Seo J-H., Lee M-Y., (2017). Heat transfer characteristics of the heat exchangers for refrigeration, air conditioning and heat pump systems under frosting, defrosting and dry/wet conditions-A review, Applied Thermal Engineering, 113, 1071-1087.

[4] Saidur, R., Masjuki, H.H., Choudhury, I.A., (2002). Role of ambient temperature, door opening, thermostat setting position and their combined effect on refrigerator- freezer energy consumption, Energy Conversion and Management, 43(6), 845- 854.

[5] Mader, G. and Thybo, C., (2012). A new method of defrosting evaporator coils, Applied Thermal Engineering, 39, 78-85.

[6] Ge, T.S., Dai J.S., Wang, R.Z. (2011). Performance study of silica gel coated fin-tube heat exchanger cooling system based on a developed mathematical model, Energy Conversion and Management, 52, 2329-2338.

[7] Lawrance, J.M.V. and Evans J.A., (2008) Refrigerant flow instability as a means to predict the need for defrosting the evaporator in a retail display freezer cabinet, International Journal of Refrigeration, 31(1), 107112 .

[8] Li, Z., Zhao D., Ding G., Ren T., Miao S., Han X, Noda T., (2017) Improving defrosting performance by controlling frost distribution to match defrosting heat distribution in frost-free household refrigerators, International Journal of Refrigeration, 77, 136-148.

[9] Yoon Y., Jeong H., Lee K., (2018) Adaptive defrost methods for improving defrosting efficiency of household refrigerator, Energy Conversion and Management, 57, 511-516.

[10] Harrington, L., Aye, L., Fuller, B., (2018) Energy impacts of defrosting in household refrigerators: Lessons from field and laboratory measurements, International Journal of Refrigeration, 86, 480-494.

[11] Bansal P., Fothergill, D., Fernandes, R., (2010) Thermal analysis of the defrost cycle in a domestic freezer, International Journal of Refrigeration, 33, 589-599

[12] Knabben, F.T., Hermes, C.J.L., Melo C. (2011) In-situ study of frosting and defrosting processes in tubefin evaporators of household refrigerating appliances, International Journal of Refrigeration, 34 , 2031-204.1.

[13] Özkan D.B., Özil E., (2006) Experimental study on the effect of frost parameters on domestic refrigerator finned tube evaporator coils, Applied Thermal Engineering, 26, 2490-2493.

[14] Zhang L., Fujinawa, T., Saikawa, M., (2016), Theoretical study on a frost-free household refrigeratorfreezer, International Journal of Refrigeration, 62, 60-71. 